\title{
Development of Charging Infrastructure and Subsidies for Promoting Electric Vehicles
}

\author{
Kiyoshi Arakawa \\ Department of Social Information Studies, Otsuma Women's University, Tokyo, Japan \\ Email: karakawa@otsuma.ac.jp
}

How to cite this paper: Arakawa, K. (2018) Development of Charging Infrastructure and Subsidies for Promoting Electric Vehicles. Theoretical Economics Letters, 8, 2006-2023.

https://doi.org/10.4236/tel.2018.811131

Received: June 22, 2018

Accepted: July 30, 2018

Published: August 2, 2018

Copyright $\odot 2018$ by author and Scientific Research Publishing Inc. This work is licensed under the Creative Commons Attribution International License (CC BY 4.0).

http://creativecommons.org/licenses/by/4.0/

(c) (i) Open Access

\begin{abstract}
This paper clarifies an effect of policy on the development of charging infrastructure and subsidies for promoting electric vehicles (EVs). Due to the long-term function of charging infrastructure, this paper constructs a multiple-period model to analyze policy effects on the diffusion of EVs from a long-term perspective. This paper shows that charging infrastructure and subsidy encourage innovation on increasing the battery capacity of EVs. Because intertemporal cost allocation can be executed in the development of a charging infrastructure with a subsidy, a policy with a long-term perspective can enhance the charging infrastructure and promote EVs effectively.
\end{abstract}

\section{Keywords}

Electric Vehicles, Charging Infrastructure, Innovations, Subsidies, Multiple-Period Models

\section{Introduction}

Due to growing concerns regarding automobile exhaust gas in local areas and the issue of climate change on a global level, the development and implementation of more environmentally friendly vehicles have become urgent issues. Electric vehicles (EVs) are expected to have an excellent environmental performance because they do not produce exhaust gas emissions. The move toward EVs is now a global trend and some European and Asian countries are considering policies to prohibit of the sales of gasoline vehicles (GVs) in the future. However, because of the high price and short cruising range of EVs, these vehicles have not prevailed in the current market ${ }^{1}$.

In this paper, we analyze a policy for promoting EVs in terms of two instru${ }^{1} \mathrm{EVs}$ constituted about $1 \%$ of sales in major countries in 2016 (IEA, [1]). See Nieuwenhuis [2] for more details. 
ments: 1) a subsidy for purchasing EVs (an economic instrument) and 2) developing charging infrastructure (an organizational instrument). Many empirical studies on economic instruments have demonstrated a strong relationship between subsidies and diffusions of EVs. For example, Hidrue et al. [3] show that consumers with EVs would pay an amount of money ten times larger than the rest of consumers to avoid a one-dollar increase in the price of a gallon equivalent of fuel. Krause et al. [4] find that consumers would like to consider buying EVs if monetary incentives were made available to them².

On the other hand, to the best of the author's knowledge, there exist no articles that explicate the theoretical aspects of economic instruments with the exception of Arakawa [8]. Arakawa [8] analyzes the effect of a subsidy for purchasing EVs on an automobile company's strategy on EVs and on consumer behavior, and finds that both subsidies and increased battery capacity promote the diffusion of EVs with practically adequate performances.

To minimize the disadvantage of EVs' short cruising ranges, the development of charging infrastructure is critical. Many studies on charging infrastructure as an organizational instrument concern the profitability of charging stations. For example, Schroeder and Traber [9] find that an investment in charging stations is hardly profitable in the early stage of EV diffusion due to low uptake rates and high uncertainty. They insist that giving charging operators a grid tariff exemption could improve the environment for investment.

Peterson and Michalek [10] compare vehicle purchase subsidies linked to battery capacities and subsidies for installing charging stations. They find empirically that in terms of cost-effectiveness, subsidizing an EV is more advantageous than charging infrastructure installation. Arakawa [11] analyzes subsidies for purchasing EVs and developing charging infrastructure from a theoretical aspect. He finds that an effective policy for promoting EVs aims first at expanding the EV market by developing charging infrastructure followed by improving EV performance.

Based on an awareness of the issues described above, we analyze the effects of two policy instruments, developing charging infrastructure and granting subsidies for purchasing EVs, on the diffusion of EVs by constructing a multi-period model of EV market. The results of this paper are as follows. Social welfare can be improved by a policy that combines the development of charging infrastructure and purchase subsidy where the amount of which depends on the purchase price of the EV. Further, developing charging infrastructure can increase innovation on battery capacity. Therefore, a policy for promoting EVs with a long-term perspective allows for the intertemporal allocation of development costs and promotes the diffusion of EVs.

This paper is organized as follows. The next section models the EV market

${ }^{2}$ Additional examples in the literature focused on hybrid vehicles. Gallagher and Muehlegger [5] show that the state tax incentive has a significant impact on consumer adoption of HVs. Jenn et al. [6] find that the tax credit has a highly positive effect on sales of HVs. Beresteanu and Li [7] find that income tax incentives, as well as gasoline prices, have a significant positive impact on the HV sales. 
based on vertical product differentiation. Section 3 analyzes the effect of charging infrastructure and the purchase subsidy on EV market under the one-period model. In Section 4, we analyze a two-period model and then conduct numerical analyses for three-, four-, and five-period models. Section 5 concludes the paper.

\section{Model for the EV Market}

Let us model the EV market. Because this market is extremely small compared with the market for GVs, we assume that EV market does not affect the GV market. Further, we assume that a potential consumer considering buying an EV does not make comparisons with GVs. Thus, the GV market also does not affect the EV market. That is, the EV market is a niche and is established independently from the GV market. We also assume that the EV market consists of a monopolistic automobile company that supplies only one kind of $\mathrm{EV}^{3}$. Because the basic running performance of EVs is fulfilled, a consumer considering buying an EV is assumed to be concerned only with the vehicle's battery capacity. Generally, large battery capacity is preferable because it is directly related to the cruising range of the EV. However, because a rechargeable battery is expensive and heavier, the price of an EV that mounts a battery with large capacity is also expensive. Therefore, there exists a trade-off relation between a size of battery capacity and the price of an EV. The indirect utility of a consumer considering buying $\mathrm{EV}$ is defined as $u=\theta s-p+S$, where $\theta$ is the marginal willingness to pay, $s$ is a quality of EV, and $S$ is the amount of subsidy. A continuum of consumers of mass $\bar{\theta}$ is uniformly distributed over the interval $[0, \bar{\theta}]$ with density equal to unity. The total market size is $\bar{\theta}$ which is assumed to be large enough. We assume that consumers with $\theta$ larger than $\bar{\theta}$ do not buy EVs, though their willingness to pay for EVs is high. It is highly possible that they have deep interests in factors such as comfortability and running performance of a vehicle. In such cases, they choose luxury GVs that attach great importance to such factors.

Let us define a quality of EV as follows. Though consumer utility decreases with an increasing number of charging times, increasing the battery capacity improves consumer utility because large battery capacity reduces the number of charging times. Thus, EV quality improves with increasing battery capacity. However, insufficient charging infrastructure reduces consumer utility due to a disruption of comfortability for long-distance driving. Furthermore, insufficiency of charging infrastructure will be further exacerbated when EVs become popular. That is, consumer utility is affected by the status of charging infrastructure and the number of EVs owned. Therefore, EV quality is determined not only by battery capacity, but also by the available charging infrastructure; i.e., charging infrastructure per EV. Based on the concept described above, EV quality is defined as $e=k v / h$, where $k$ is a quantity of charging infrastructure, i.e., the ${ }^{3}$ For example, as of 2017 in Japan, only Nissan Leaf and Mitsubishi i-MiEV are commercially available as mass-produced EVs. This assumption is appropriate because their vehicle sizes and battery capacities are different and their competitive relationship can be assumed not to be fierce. 
number of charging facilities, $v$ is battery capacity, and $h$ is the number of EVs owned.

We assume here that all traveling distances of consumers are the same; therefore, the electric power demands are also same. That is, even though battery capacity increases and the number of charging events decreases, the total charging time required does not change. In a multi-period model, though EVs with different battery capacities intermingle, this assumption enables us to treat EVs in all periods the same, regardless of differences in their battery capacities when the quantity of charging infrastructure per EV is calculated.

Here, we assume that when a consumer considers buying an EV, though the number of EVs owned $h$ is not determined, he treats $h$ as exogenous and does not consider the effect of his purchase on $h$. This is a reasonable assumption because the number of EVs demanded $q$ and the number of EVs owned $h$ will coincide if all consumers decide whether or not to buy EVs at the same time. Thus, we obtain equilibrium $h$ by first obtaining $q$ given $h$, and then solving $h=q$.

A consumer buys an EV if he obtains a positive net surplus; that is, $u=\theta k v / h-p+S \geq 0$. Thus, the demand for EVs is obtained as

$$
q=\bar{\theta}-\frac{(p-S) h}{k v} .
$$

A consumer does not buy an EV otherwise. A consumer who does not buy an $\mathrm{EV}$ is assumed to use public transportation. We do not set further assumptions on their behavior.

The manufacturer of EVs determines the EV price and battery capacity so as to maximize his profit. For simplicity, we assume that EV production costs depend only on the battery capacity, which is represented as $\mathrm{CV}^{2}$. Because we do not consider quality factors other than battery capacity, the costs of those factors become fixed values. Thus, considering these costs does not affect results meaningfully. That is, to increase battery capacity, the cost grows exponentially. Therefore, the profit of the manufacturer is defined as

$$
\pi=q\left(p-c v^{2}\right) .
$$

In this paper, the government develops charging infrastructure. In reality, however, private business operators basically install charging facilities based on their own judgment. Thus, normally, the development of charging infrastructure by private business operators should be modeled. However, it is difficult for private operators managing a charging station to earn a profit in the short-run [12] [13]. This is the reason why large amounts of subsidy are granted for installing charging facilities. In other words, the installation of charging infrastructure is under strong control of the government subsidy. Thus, for simplicity, this paper assumes that the government develops the charging infrastructure. It needs to be complexified the model for considering a service provider of charging facility that survives under the existence of a subsidy. It seems not to be meaningful to include the service provider into the model because the final decision for instal- 
ling a charging facility made by the service provider is strongly affected by the amount of subsidy.

Because our aim is to obtain optimal values for the charging infrastructure and subsidy rate, we have to define social surplus. Consumer surplus is defined as

$$
C S=\int_{\frac{(p-S) h}{k v}}^{\bar{\theta}}\left(\frac{\theta k v}{h}-p+S\right) \mathrm{d} \theta .
$$

Social surplus is defined as the sum of consumer surplus, profit, cost of developing charging infrastructure, and cost of granting subsidy $q S$. Thus, social surplus is written as $S S=C S+\pi-b k^{3}-q S$. Note that the cost of developing charging infrastructure is assumed to increase exponentially with the quantity of infrastructure and is defined as $b k^{3}$. In a multi-period model, the cost of developing charging infrastructure is assumed to start from zero every period. Therefore, for example, when a certain amount of infrastructure is to be developed, the cost for completion within one period is larger than that within two periods. The reason for the assumption is as follow. In the short term, the more charging infrastructure that is developed the higher the costs because finding preferable places for installing charging facilities becomes more difficult. However, development costs may decrease as time passes because preferable places for chargers are supplied periodically from, for example, changes of locational use. Thus, it is reasonable to assume for simplicity that the development costs of charging infrastructure start from zero in each period.

In this paper, we analyze two types of purchase subsidy for EVs: 1) an ad valorem subsidy whose amount depends on the EV purchase price and 2) a specific subsidy whose amount depends on the battery capacity. For example, the current purchase subsidy for EVs in Japan is regarded as a specific subsidy because the subsidy amount is calculated basically by a travel distance per charge, which is closely related to battery capacity. However, prior to 2015, the purchase subsidy for EVs was regarded as an ad valorem subsidy because the subsidy amount was calculated basically by the EV purchase price. Thus, because the subsidy calculation methods have been altered often, it is an important problem to clarify the differences in these two types of EV purchase subsidies.

The EV market is modeled as follows. First, the government determines policy for developing charging infrastructure and granting subsidies for the entire planning period; that is, it adopts a long-term perspective. Given the policy, the manufacturer determines the EV price and battery capacity, and consumers consider buying EVs every period. We do not consider uncertainty in the model.

In the following section, we analyze the effect of charging infrastructure and the purchase subsidy on EV market under the one-period model as a benchmark.

\section{One-Period Model Analysis}

In this section, we clarify an effect of the two policy instruments on the diffusion 
of EVs by analyzing the EV market established for one period as a benchmark. In the following, we analyze three cases: 1) no subsidy; 2) ad valorem subsidy; and (3) specific subsidy.

\subsection{No Subsidy}

No subsidy implies that $S=0$. By plugging Equation (1) into Equation (2) and maximizing profit with respect to $p$ and $v$, the following solutions are obtained:

$$
p=\frac{2}{9 c}\left(\frac{k \bar{\theta}}{h}\right)^{2} ; v=\frac{k \bar{\theta}}{3 c h}
$$

Thus, maximized profit is $\pi=k^{2} \bar{\theta}^{3} /\left(27 c h^{2}\right)$.

By plugging Equation (3) into Equation (1), the demand for EVs is obtained as $q=\bar{\theta} / 3$. This equation shows that the demand for EVs is determined by the maximum willingness to pay for an EV $\bar{\theta}$ and is independent of quantity of charging infrastructure $k$ and the number of EVs owned $h$. Further, because the number of EVs owned equals to demand for EVs, by solving $h=q$, we obtain the number of EV owned as $h=\bar{\theta} / 3$. Therefore, we have following equilibrium:

$$
p=\frac{2 k^{2}}{c} ; v=\frac{k}{c} ; \pi=\frac{k^{2} \bar{\theta}}{3 c} .
$$

Both EV price and battery capacity increase with the number of charging facilities. Because improving charging infrastructure increases willingness to pay for EVs, the manufacturer can raise the EV price without extending the battery capacity. However, the above result shows that in that case the manufacturer loads battery with enlarged capacity on EVs to raise EV price. This implies that the development of charging infrastructure has an effect of inducing innovation to extend the battery capacity. In a similar way, the development of charging infrastructure increases profit.

According to the above results, the development of charging infrastructure increases the price of EVs, battery capacity, and profit. However, the number of EVs owned is independent of the number of charging facilities. Although the number of EVs owned is determined by a consumer with $\theta$ who obtains zero utility from purchasing an EV, the development of charging infrastructure does not affect the purchase decision of such a consumer. That is because $u=k_{1}^{2}(3 \theta-2 \bar{\theta}) /(c \bar{\theta})$; though $k$ affects absolute level of the utility, it does not affect $\theta$ that equalizes the utility to be zero.

Here, consumer and social surplus are written, respectively, as follows:

$$
\begin{gathered}
C S=\int_{\frac{p h}{k v}}^{\bar{\theta}}\left(\frac{\theta k v}{h}-p\right) \mathrm{d} \theta=\frac{k^{2} \bar{\theta}}{6 c} . \\
S S=C S+\pi-b k^{3}-q \gamma p=\frac{k^{2}(-2 b c k+\bar{\theta})}{2 c} .
\end{gathered}
$$


The quantity of charging infrastructure maximizing social surplus is obtained as

$$
k=\frac{\bar{\theta}}{3 b c} .
$$

Thus, in this case, social surplus is obtained as

$$
S S=\frac{\bar{\theta}^{3}}{54 b^{2} c^{3}} .
$$

\subsection{Ad Valorem Subsidy}

The amount of ad valorem subsidy is represented as $S=\gamma p$, where $\gamma$ is the ad valorem subsidy rate; that is, the ratio of the amount of subsidy to the EV purchase price. By a similar procedure, the equilibrium is obtained as follows:

$$
p=\frac{2}{9 c}\left(\frac{k \bar{\theta}}{(1-\gamma) h}\right)^{2} ; v=\frac{k \bar{\theta}}{3 c(1-\gamma) h} .
$$

We find that both the EV price and the battery capacity increase along with the quantity of charging infrastructure and the subsidy rate. In this case, the maximized profit is $\pi=k^{2} \bar{\theta}^{3} /\left(27 c(1-\gamma)^{2} h^{2}\right)$. Further, plugging Equation (6) into Equation (1), demand for EVs is obtained as $q=\bar{\theta} / 3$. Thus, we find that demand for EVs is independent of the ad valorem subsidy rate. By solving $h=q$, the number of EVs owned is obtained as $h=\bar{\theta} / 3$. Thus, equilibrium solutions are obtained as follows:

$$
p=\frac{2 k^{2}}{c(1-\gamma)^{2}} ; v=\frac{k}{c(1-\gamma)} ; \pi=\frac{k^{2} \bar{\theta}}{3 c(1-\gamma)^{2}} .
$$

The results show that both the quantity of charging infrastructure and the subsidy rate increase all equilibrium solutions. Thus, both policy instruments have the power to induce innovation with respect to battery capacity.

Let us obtain optimal values of the two policy instruments. Consumer and social surplus are written, respectively, as follows:

$$
\begin{gathered}
C S=\int_{\frac{(1-\gamma) p h}{k v}}^{\bar{\theta}}\left(\frac{\theta k v}{h}-(1-\gamma) p\right) \mathrm{d} \theta=\frac{k^{2} \bar{\theta}}{6 c(1-\gamma)} . \\
S S=C S+\pi-b k^{3}-q \gamma p=\frac{k^{2}\left(-6 b c(1-\gamma)^{2} k+(3-5 \gamma) \bar{\theta}\right)}{6 c(1-\gamma)^{2}} .
\end{gathered}
$$

The quantity of charging infrastructure and rate of ad valorem subsidy that maximizes Equation (8) are obtained as

$$
k=\frac{25 \bar{\theta}}{72 \beta c} ; \gamma=\frac{1}{5} \text {. }
$$

Therefore, social surplus under the optimal promotion policy is

$$
S S=\frac{15625 \bar{\theta}^{3}}{746496 b^{2} c^{3}} .
$$


Let us compare these results with the no subsidy case. By comparing Equation (4) and Equation (9), we find that the optimal ad valorem subsidy increases the quantity of charging infrastructure. The reason is, Equation (7) shows that while the ad valorem subsidy increases battery capacity it also increases the power of charging infrastructure to increase social surplus. Further, comparing Equation (5) and Equation (10), we find that an ad valorem subsidy improves social surplus. Based on the above results, we obtain following proposition.

Proposition 1: An ad valorem subsidy, compared with the no subsidy case, improves social surplus by increasing the quantity of charging infrastructure through greater battery capacity.

An intuitive explanation of the proposition is as follows. Because granting an ad valorem subsidy enables consumers to purchase EVs with larger battery capacity, the manufacturer has an incentive to develop and sell such EVs. In this case, the government can spread EVs equipped with a larger battery capacity further by enhancing the charging infrastructure. This mechanism improves social welfare.

\subsection{Specific Subsidy}

The amount of a specific subsidy is represented as $S=\lambda v$, where $\lambda$ is the specific subsidy rate; that is, the ratio of battery capacity to the amount of subsidy. By a similar procedure to the ad valorem subsidy case, we obtain the following equilibrium solutions:

$$
p=\frac{2(\lambda h+k \bar{\theta})^{2}}{9 c h^{2}} ; v=\frac{\lambda h+k \bar{\theta}}{3 c h} ; \pi=\frac{(\lambda h+k \bar{\theta})^{3}}{27 c h^{2} k} .
$$

Plugging Equation (11) into Equation (1), we obtain $q=(\lambda h+k \bar{\theta}) /(3 k)$. By solving $h=q$, we have $h=k \bar{\theta} /(3 k-\lambda)$. The result shows that unlike an ad valorem subsidy, a specific subsidy enlarges the EV market. Further, we obtain the following equilibrium values:

$$
p=\frac{2 k^{2}}{c} ; v=\frac{k}{c} ; \pi=\frac{k^{3} \bar{\theta}}{3 c k-c \lambda} .
$$

As with the previous two cases, both the EV price and battery capacity are increasing with the quantity of charging infrastructure. However, unlike the ad valorem subsidy, a tax rate of specific subsidy does not affect the EV price or battery capacity: it only affects the profit. Differentiating Equation (12) by a quantity of charging infrastructure, we have $\partial \pi / \partial k=3(2 k-\lambda) k^{2} \bar{\theta} /\left(c(3 k-\lambda)^{2}\right)$. Thus, when $2 k>\lambda$, i.e., when the rate of specific subsidy is relatively small, developing charging infrastructure increases the profit.

Let us obtain a socially optimal rate of specific subsidy. Consumer and social surplus are written, respectively, as

$$
\begin{gathered}
C S=\int_{\frac{(p-\lambda v) h}{k v}}^{\bar{\theta}}\left(\frac{\theta k v}{h}-p+\lambda v\right) \mathrm{d} \theta=\frac{k^{3} \bar{\theta}}{6 c k-2 c \lambda} . \\
S S=C S+\pi-b k^{3}-q \lambda v=\frac{k^{2}(-2 c(\lambda-3 k) k+(2 \lambda-3 k) \bar{\theta})}{2 c(\lambda-3 k)} .
\end{gathered}
$$


Because $\partial S S / \partial \lambda=-3 k^{3} \bar{\theta} /\left(2 c(\lambda-3 k)^{2}\right)<0$, an increase in the amount of specific subsidy reduces social surplus. Thus, we find that the socially optimal rate of specific subsidy is $\lambda=0$ and obtain following proposition.

Proposition 2: A specific subsidy does not improve social surplus.

Note that this proposition does not imply that a specific subsidy does not have the power to improve consumer surplus and profit. Because

$$
\frac{\partial C S}{\partial \lambda}=\frac{k^{3} \bar{\theta}}{2 c(\lambda-3 k)^{2}}>0 ; \frac{\partial \pi}{\partial \lambda}=\frac{k^{3} \bar{\theta}}{c(\lambda-3 k)^{2}}>0,
$$

while specific subsidy has a power to improve both consumer surplus and profit, social cost of specific subsidy is larger than social benefit of those improvements, that is, the social cost exceeds the benefit. However, this model does not consider environmental improvements through the diffusion of EVs. Therefore, by incorporating environmental improvement, the specific subsidy may contribute to society.

The following is an intuitive explanation of the difference between an ad valorem subsidy and a specific subsidy. Because the latter provides a subsidy according to battery capacity, and since battery capacity is directly related to the production cost of EVs (for a given subsidy rate), a manufacturer can effectively maximize his profit by controlling battery capacity, meaning the cost of producing EVs. On the contrary, because an ad valorem subsidy is based on EV prices rather than battery capacity, a manufacturer cannot maximize his profit effectively compared to a specific subsidy. Rather, a manufacturer can discretionally maximize his profit and obtain a large surplus under a specific subsidy. Therefore, as in Proposition 2, a specific subsidy cannot improve social surplus 4 .

The result implies that an ad valorem subsidy is socially more preferable than a specific subsidy ${ }^{5}$. However, the current actual purchase subsidy is equivalent to the specific subsidy in this model. Thus, this result provides a suggestion that to justify the specific subsidy, it is necessary to make a system that improves the cost-effectiveness of the specific subsidy ${ }^{6}$.

\section{Multi-Period Analysis}

Charging infrastructure provides a long-term effect on the EV market. Specifically, by developing sufficient charging infrastructure in the primary period, EVs

${ }^{4}$ Arakawa [14] compares a specific and an ad valorem tax (subsidy) from the welfare perspective by developing a vertically differentiated oligopoly model with endogenous product selection. A specific tax adds marginal costs for firms and weakens price competition. As a result, he finds that an ad valorem tax is better than a specific one. See Keen [15], Salanié [16], and Slemrod and Gillitzer [17] for more details.

${ }^{5}$ Arakawa [8] models the EV market where consumers with different driving distances coexist. $\mathrm{He}$ clarifies theoretically that a specific subsidy is socially better than an ad valorem subsidy. The reason is that a specific subsidy induces an automaker to supply EVs with greater battery capacity; consumers with long-distance drive purchase EVs.

${ }^{6}$ For example, a vehicle-to-grid system, where EVs are connected with the power grid, can accrue social benefits (Kempton and Letendre [18], and Liu et al., [19]). Because the benefit is increased through increased battery capacity, the specific subsidy may be justified owing to its ability to affect battery capacity directly. 
may be effectively diffused in the latter periods. Thus, in this section, an effect of the two policy instruments on the diffusion of EVs is clarified by multi-period analysis. Here we only analyze the ad valorem subsidy ${ }^{7}$.

The manufacturer is permanent, whereas consumers considering buying EVs are exchanged every period. Because neither the EV price nor battery capacity is stock variables, the manufacturer determines those variables without a long-term perspective. Thus, both consumers and the manufacturer maximize utility and profit, respectively, within each period. Only the government makes policy for promoting EVs from a long-term perspective.

A consumer who purchases an EV at some point will keep driving the EV thereafter. Though a consumer who has already purchased EV is not affected by the EV purchase subsidy, they are affected by the development of charging infrastructure through an improved charging environment. Thus, the surplus to consumers that already have purchased an EV has to be included in the social surplus.

In this section, we first analyze the two-period model. To clarify an effect of policy with a long-term perspective, we compare analytically the result of policy with short-term perspective, i.e., policy determined every period. Then, we numerically clarify an effect of a policy from the perspective of a 3 - 5-period. In the following, let subscripts on the variables represent a period.

\subsection{Two-Period Model Analysis}

The equilibrium of consumers and the manufacturer in period 1 has been obtained in the former section. We rewrite social surplus in period 1, i.e. Equation (8), as

$$
S S_{1}=\frac{k_{1}^{2}\left(-6 b c\left(1-\gamma_{1}\right)^{2} k_{1}+\left(3-5 \gamma_{1}\right) \bar{\theta}\right)}{6 c\left(1-\gamma_{1}\right)^{2}} .
$$

In period 2, $k_{1}$ and $v_{1}$ are given. Indirect utility of a consumer considering buying an EV is $u_{2}=\theta s_{2}-\left(1-\gamma_{2}\right) p_{2}$. EV quality is defined as $e_{2}=\left(k_{1}+k_{2}\right) v_{2} /\left(h_{1}+h_{2}\right)$, where $h_{1}$ is the number of EVs owned in period 1 (note that this is given in this period). This EV quality includes the quantity of charging infrastructure and the number of EVs owned in period 1. Thus, EV quality in period 2 increases with the quantity of charging infrastructure in period 1 while it decreases with the number of EVs owned in that period.

By using a similar procedure, we have the following:

$$
p_{2}=\frac{2}{9 c}\left(\frac{\left(k_{1}+k_{2}\right) \bar{\theta}}{\left(1-\gamma_{2}\right)\left(h_{1}+h_{2}\right)}\right)^{2} ; v_{2}=\frac{\left(k_{1}+k_{2}\right) \bar{\theta}}{3 c\left(1-\gamma_{2}\right)\left(h_{1}+h_{2}\right)} \text {. }
$$

Thus, the maximized profit in period 2 is obtained as $\pi_{2}=\left(k_{1}+k_{2}\right)^{2} \bar{\theta}^{3} /\left(27 c\left(1-\gamma_{2}\right)^{2}\left(h_{1}+h_{2}\right)^{2}\right)$. Further, with $h_{1}=\bar{\theta} / 3$, we have

${ }^{7}$ Numerical analysis using Mathematica with same parameters used in the latter analysis shows that an optimal specific subsidy rate of 3 - 5-period is zero. That is, the specific subsidy does not improve social surplus under the long-term perspective. 


$$
q_{2}=h_{2}=\frac{\bar{\theta}}{3} .
$$

We find that for period 1, the number of EVs owned depends only on the maximum of willingness to pay for an EV. Thereby, we have the following equilibrium:

$$
p_{2}=\frac{\left(k_{1}+k_{2}\right)^{2}}{2 c\left(1-\gamma_{2}\right)^{2}} ; v_{2}=\frac{k_{1}+k_{2}}{2 c\left(1-\gamma_{2}\right)} ; \pi_{2}=\frac{\left(k_{1}+k_{2}\right)^{2} \bar{\theta}}{12 c\left(1-\gamma_{2}\right)^{2}} .
$$

Surplus of consumers that purchase EVs in period 2 is

$$
C S_{2}=\int_{\frac{\left(1-\gamma_{2}\right) p_{2}\left(h_{1}+h_{2}\right)}{\left(k_{1}+k_{2}\right) v_{2}}}^{\bar{\theta}}\left(\frac{\theta\left(k_{1}+k_{2}\right) v_{2}}{\left(h_{1}+h_{2}\right)}-\left(1-\gamma_{2}\right) p_{2}\right) \mathrm{d} \theta=\frac{\left(k_{1}+k_{2}\right)^{2} \bar{\theta}}{24 c\left(1-\gamma_{2}\right)} .
$$

Moreover, surplus of consumers in period 2 that have already purchased an $\mathrm{EV}$ in period 1 is obtained as

$$
C S_{1}=\int_{\frac{\left(1-\gamma_{1}\right) p_{1} h_{1}}{k_{1} \nu_{1}}}^{\bar{\theta}} \frac{\theta\left(k_{1}+k_{2}\right) v_{1}}{h_{1}+h_{2}} \mathrm{~d} \theta=\frac{5 k_{1}\left(k_{1}+k_{2}\right) \bar{\theta}}{12 c\left(1-\gamma_{1}\right)} .
$$

Note that EV price in period $1 p_{1}$ is given in this period. Thereby, social surplus in period 2 is obtained as

$$
S S_{2}=C S_{2}+C S_{1}+\pi_{2}-b k_{2}^{3}-q_{2} \gamma_{2} p_{2} .
$$

\subsubsection{Short-Term Perspective}

Here, we analyze policy with short-term perspective, where the two policy instruments are determined every period. The optimal policy in period 1 is obtained by maximizing social surplus, i.e. Equation (13). On the other hand, the optimal policy in period 2 can be obtained by maximizing social surplus, i.e. Equation (16), given the optimal policy in period 1. Therefore, optimal policy is obtained as follows:

$$
k_{s 1}=k_{s 2}=\frac{25 \bar{\theta}}{72 \beta c} ; \gamma_{s 1}=\gamma_{s 2}=\frac{1}{5},
$$

where subscript $s$ represents the policy with a short-term perspective.

The results show that in the short-term perspective, optimal policy instruments are the same across two periods. Because both consumers and the manufacturer take maximizing behaviors every period, their decisions are also the same across both periods. Thus, when the government takes maximizing behavior every period, the optimal policy in each period becomes the same. Social surplus, in this case, is

$$
S S_{s 1}+S S_{s 2}=\frac{0.167449 \bar{\theta}^{3}}{b^{2} c^{3}} .
$$

\subsubsection{Long-Term Perspective}

Here, we analyze the optimal policy on developing charging infrastructure and the EV subsidy across two periods; i.e., the policy with a long-term perspective. The government takes the long-term perspective and maximizes social surplus 
obtained by the sum of two periods; i.e., the sum of Equation (13) and Equation (16). Note that here we do not discount social surplus because we regard two periods as a relatively short time span. We assume further that EVs owned and charging infrastructure developed do not deteriorate within five periods.

Let us obtain the optimal policy under a long-term perspective. We have optimal policy instruments that maximize the sum of social surpluses within two periods. Note that the subscript $l$ represents the policy under a long-term perspective:

$$
\gamma_{l 1}=\frac{7 k_{1}+5 k_{2}}{15 k_{1}+5 k_{2}} ; \gamma_{l 2}=\frac{1}{5} .
$$

The optimal quantities of charging infrastructure under Equation (19) are

$$
k_{l 1}=\frac{1.09324 \bar{\theta}}{b c} ; k_{l 2}=\frac{0.709006 \bar{\theta}}{b c} .
$$

We find that optimal quantity of charging infrastructure in period 2 is larger than that in period 1. Plugging Equation (20) into Equation (19), we obtain the optimal rates of subsidy as follows:

$$
\gamma_{l 1}=0.561468 ; \gamma_{l 2}=\frac{1}{5} \text {. }
$$

According to the above results, we have the following proposition.

Proposition 3: In the optimal policy with a two-period perspective, both the quantity of charging infrastructure and the rates of subsidy decrease over time.

Under these optimal instruments, the sum of social surpluses is obtained as

$$
S S_{l 1}+S S_{l 2}=\frac{0.831513 \bar{\theta}^{3}}{b^{2} c^{3}} .
$$

Comparing this and Equation (18), we find that policy with a long-term perspective improves social surplus more than that with a short-term perspective. Moreover, because

$$
S S_{l 1}=-\frac{1.10706 \bar{\theta}^{3}}{b^{2} c^{3}} ; S S_{l 2}=\frac{1.93857 \bar{\theta}^{3}}{b^{2} c^{3}},
$$

we find that social surplus in period 1 is negative while in period 2 it is positive. This shows that the social cost of the two policy instruments is allocated intertemporally. That is, by incurring a large amount of social cost and developing sufficient charging infrastructure in period 1, the government can induce the manufacturer to innovate on battery capacity. In period 2, taking sufficient charging infrastructure developed in period 1 for granted, and reducing social cost by lowering development of charging infrastructure and subsidy amount, government can largely improve social surplus.

\subsection{Analysis of More than Three-Period Models}

When a policy plan period exceeds three periods, we cannot obtain an analytical result. Thus, we numerically analyze the three-to five-period models to clarify 
the policy effect under a long-term perspective. In numerical analyses, we solve maximization problems numerically with Mathematica by using parameters as $\bar{\theta}=b=c=1$ and discount rate as 0.05 .

First, let us analyze the subsidy rate. Figure 1 shows that as the planning period is prolonged, the subsidy rate in period 1 increases. This implies that as policy extends, it is socially preferable to induce consumers to purchase EVs by increasing the subsidy rate. Further, a subsidy rate decreases over time and, regardless of a plan period, the subsidy rate in the final period becomes one-fifth, which is the same as one-period analysis. The reason is that in the final period, the government does not have to consider afterward, and benefit of subsidy is obtained only by consumers purchasing EVs in the final period, the subsidy rate of the final period coincides with that of the one-period model.

Improved battery capacity that results from innovation reflects the effect of the purchase subsidy. Figure 2 shows that as the policy period extends, battery capacity in period 1 is increased whereas battery capacity decreases over time. Because the manufacturer can supply more expensive EVs as the subsidy rate increases, they have an incentive to increase the battery capacity. Thus, changes in battery capacity parallel changes in the subsidy rate.

Next, let us consider the charging infrastructure. Figure 3 shows that as the plan period is extended, the quantity of charging infrastructure in period 1 increases. That is, a government policy with a longer-term perspective promotes the development of charging infrastructure and diffuses EVs more effectively. The quantity of charging infrastructure decreases over time; however, unlike the subsidy rate, as the policy period extends, the quantity of charging infrastructure in the final period increases. As described above, the government diffuses EVs by developing charging infrastructure sufficiently in spite of incurring large social cost with negative social surplus in the earlier period. After that, the government reduces social cost in order to recover incurred large social cost until then, and controls the sum of social surpluses within the plan period to be a large positive value. Because intertemporal cost allocation is more effective as a policy period extends, the quantity of charging infrastructure in the final period increases with a longer-term perspective.

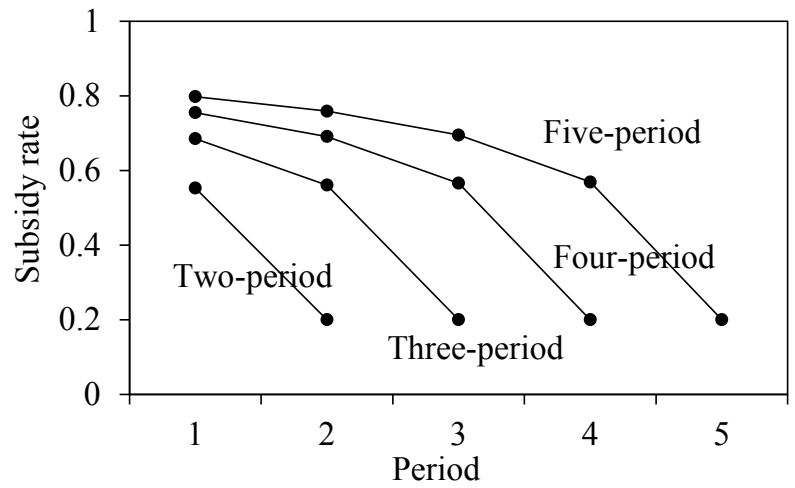

Figure 1. Optimal subsidy rates. 


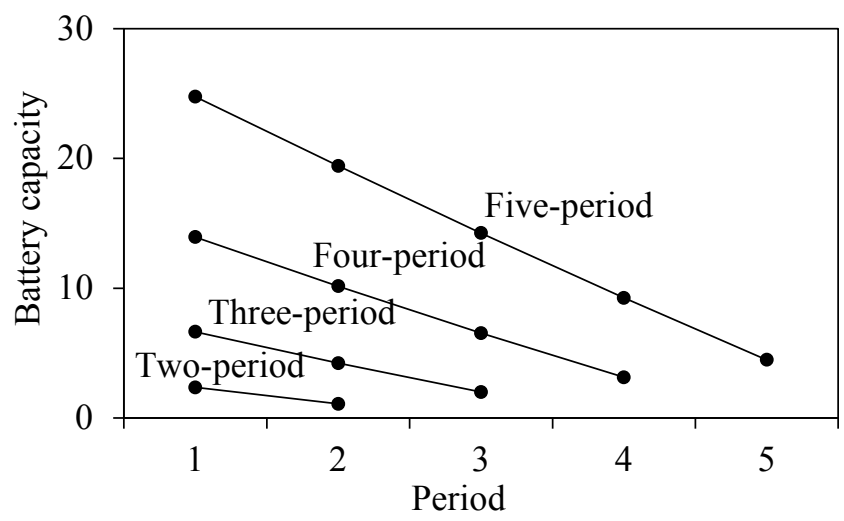

Figure 2. Battery capacity under the optimal policy.

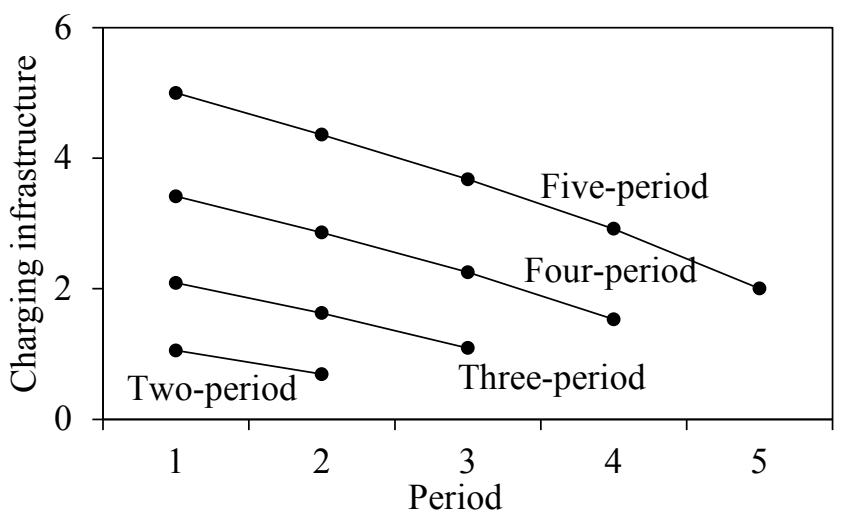

Figure 3. Optimal charging infrastructure.

The effect of intertemporal cost allocation can be seen by the change in social surplus. Figure 4 shows the change in social surplus for each plan period, for example, in five-period model. From the figures, we find that social surplus in period 1 is negative, whereas social surplus increases over time to become positive in the later period. Figure 5 shows that as the policy period extends, the sum of social surpluses within a plan period increases exponentially. It is evident that compared with the short-term perspective, a policy that promotes EVs increases its power with a longer-term perspective.

Existing owners of EVs must be considered in the multi-period model as they benefit from newly developed charging infrastructure. As a policy extends and because the existing owners of EVs also increase, government has a large incentive to develop charging infrastructure. Further, a development of charging infrastructure induces innovation on battery capacity. That is, with a longer-term perspective, both the quantity of charging infrastructure and battery capacity increase.

In summary, we find that with a longer-term perspective, the subsidy rate, quantity of charging infrastructure, and battery capacity in period 1 increase, whereas they decrease over time. Further, we find that as a policy is extended, the sum of social surpluses within the plan period increase exponentially. 


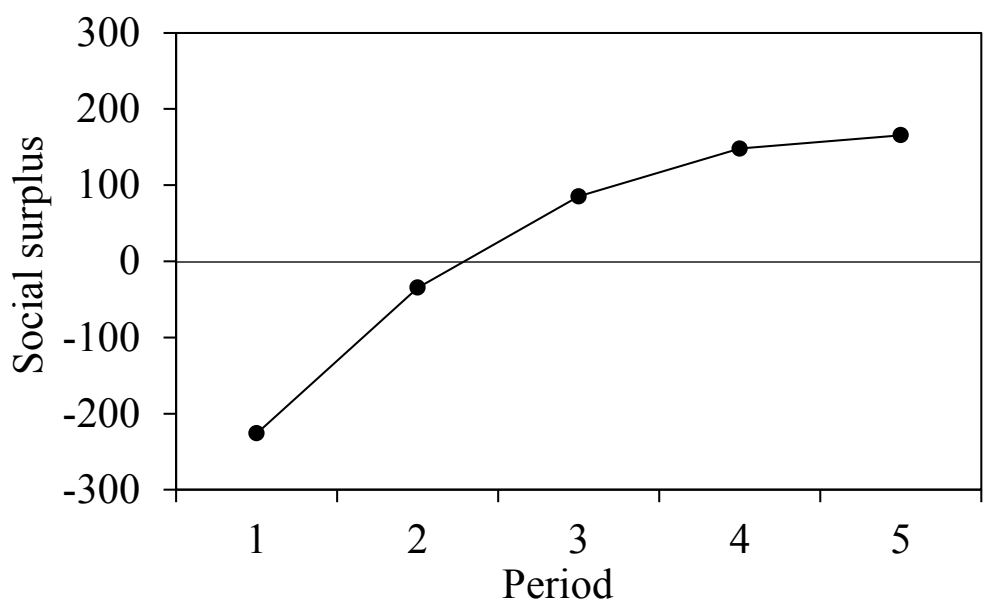

Figure 4. Social welfare under a five-period perspective.

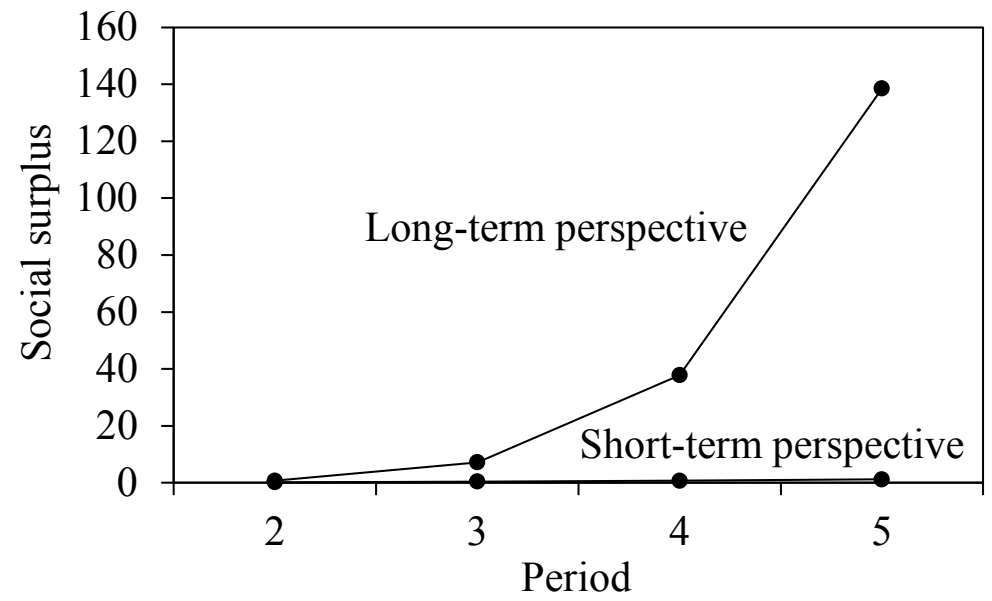

Figure 5. Social welfare under long- and short-term perspectives.

Though charging infrastructure increases as a plan period extends, the number of EVs owned also increases. Thus, the effect of policy cannot be understood completely with the quantity of charging infrastructure. The purpose of developing charging infrastructure is to improve EV quality by providing a good charging environment. Thus, the effect of policy on charging infrastructure can be understood in detail by analyzing the effect of a prolonged plan period on EV quality. Figure 6 shows that EV quality is the highest in period 1 then decreases over time. Further, as the plan period is extended, EV quality in period $1 \mathrm{im}$ proves. Thus, EV quality as determined by the quantity of charging infrastructure, battery capacity, and the number of EVs owned can be improved with a longer-term perspective. The above is gathered into the following policy implication.

Policy implication: Under a longer-term perspective, the government can improve significantly the sum of social surpluses within the plan period by improving EV quality through increasing the subsidy rate, the quantity of charging infrastructure, and battery capacity in the early periods. 


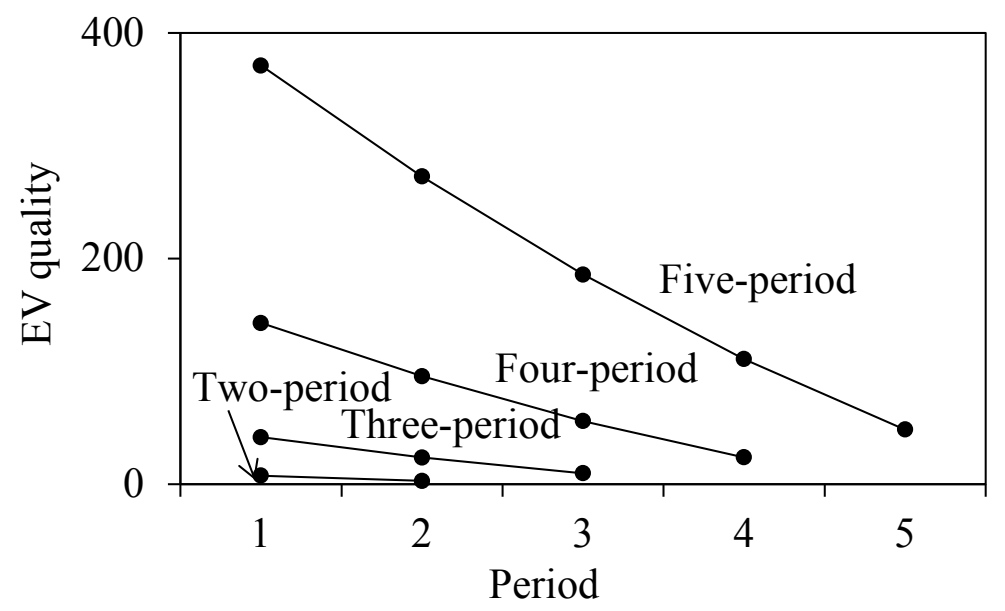

Figure 6. EV quality under the optimal policy.

\section{Conclusions}

The purpose of this paper is to clarify an effect of policy for promoting EVs on social welfare. Thus, we construct multi-period model and analyze effect of developing charging infrastructure and subsidies for purchasing EVs on the diffusion of EVs. The results obtained in this paper are as follows. Developing charging infrastructure by granting subsidies has an effect to induce innovation to expand battery capacity. Further, because the government can allocate the cost of developing charging infrastructure and subsidies intertemporally, it can diffuse EVs effectively by prolonging the plan period, i.e., by having a longer-term perspective.

In this paper, we clarify that it is necessary for effective diffusion of EVs to develop charging infrastructure under a long-term perspective. However, the actual development of charging infrastructure may do not have such a long-term perspective, hence, EVs have not been diffused sufficiently. It will be important to develop policies that demonstrate effective effect of charging infrastructure to promoting innovation on battery capacity. In this case, it is anticipated that the effect is enhanced further when competition in research and development of EVs among automobile companies intensifies. Thus, by extending the model in this paper to an oligopolistic market, we can analyze the evolution of the EV market. Further, by including mutual interaction with the GV market into the model, we can clarify a policy that accomplishes an optimal transition from GVs to EVs. These are future tasks.

\section{Conflicts of Interest}

The authors declare no conflicts of interest regarding the publication of this paper.

\section{References}

[1] IEA (2017) Global EV Outlook 2017. OECD/IEA, Paris. 
[2] Nieuwenhuis, P. (2012) The Challenge of Decarbonizing the Car. In: Nilsson, M., Hillman, K., Rickne, A. and Magnusson, T., Eds., Paving the Road to Sustainable Transport: Governance and Innovation in Low-Carbon Vehicles, Routledge, New York.

[3] Hidrue, M.K., Parsons, G.R., Kempton, W. and Gardner, M. (2011) Willingness to Pay for Electric Vehicles and Their Attributes. Resource and Energy Economics, 33, 686-705. https://doi.org/10.1016/j.reseneeco.2011.02.002

[4] Krause, R.M., Carley, S.R., Lane, B.W. and Graham, J.D. (2013) Perception and Reality: Public Knowledge of Plug-In Electric Vehicles in 21 U.S. Cities. Energy Policy, 63, 433-440. https://doi.org/10.1016/j.enpol.2013.09.018

[5] Gallagher, K.S. and Muehlegger, E. (2011) Giving Green to Get Green? Incentives and Consumer Adoption of Hybrid Vehicle Technology. Journal of Environmental Economics and Management, 61, 1-15. https://doi.org/10.1016/j.jeem.2010.05.004

[6] Jenn, A., Azevedo, I. and Ferreira, P. (2013) The Impact of Federal Incentives on the Adoption of Hybrid Electric Vehicles in the United States. Energy Economics, 40, 936-942. https://doi.org/10.1016/j.eneco.2013.07.025

[7] Beresteanu, A. and Li, S. (2011) Gasoline Prices, Government Support, and the Demand for Hybrid Vehicles in the United States. International Economic Review, 52, 161-182. https://doi.org/10.1111/j.1468-2354.2010.00623.x

[8] Arakawa, K. (2016) Comparing Regulation and Fiscal Incentives for the Promotion of Electric Vehicles. Studied in Applied Economics, 10, 19-39.

[9] Schroeder, A. and Traber, T. (2012) The Economics of Fast Charging Infrastructure for Electric Vehicles. Energy Policy, 43, 136-144.

https://doi.org/10.1016/j.enpol.2011.12.041

[10] Peterson, S. and Michalek, J. (2013) Cost-Effectiveness of Plug-In Hybrid Electric Vehicle Battery Capacity and Charging Infrastructure Investment for Reducing US Gasoline Consumption. Energy Policy, 52, 429-438.

https://doi.org/10.1016/j.enpol.2012.09.059

[11] Arakawa, K. (2015) The Subsidy for Promotion of Electric Vehicles and Improvement of Charging Infrastructure. Otsuma Journal of Social Information Studies, 24, $1-11$.

[12] Madina, C., Zamora, I. and Zabala, E. (2016) Methodology for Assessing Electric Vehicle Charging Infrastructure Business Models. Energy Policy, 89, 284-293. https://doi.org/10.1016/j.enpol.2015.12.007

[13] San Román, T.G., Momber, I., Abbad, M.R. and Sánchez Miralles, Á. (2011) Regulatory Framework and Business Models for Charging Plug-In Electric Vehicles: Infrastructure, Agents, and Commercial Relationships. Energy Policy, 39, 6360-6375. https://doi.org/10.1016/j.enpol.2011.07.037

[14] Arakawa, K. (2012) The Comparison between Specific and Ad Valorem Taxation under Vertically Differentiated Oligopoly. Studied in Applied Economics, 6, 85-104.

[15] Keen, M.J. (1998) The Balance between Specific and Ad Valorem Taxation. Fiscal Studies, 19, 1-37. https://doi.org/10.1111/j.1475-5890.1998.tb00274.x

[16] Salanié, B. (2011) The Economics of Taxation. 2nd Edition, The MIT Press, Cambridge, Massachusetts.

[17] Slemrod, J. and Gillitzer, C. (2014) Tax Systems. The MIT Press, Cambridge, Massachusetts. https://doi.org/10.7551/mitpress/9780262026727.001.0001

[18] Kempton, W. and Letendre, S.E. (1997) Electric Vehicles as a New Power Source for Electric Utilities. Transportation Research Part D: Transport and Environment, 2, 
157-175. https://doi.org/10.1016/S1361-9209(97)00001-1

[19] Liu, L., Kong, F., Liu, X., Peng, Y. and Wang, Q. (2015) A Review on Electric Vehicles Interacting with Renewable Energy in Smart Grid. Renewable and Sustainable Energy Reviews, 51, 648-661. https://doi.org/10.1016/j.rser.2015.06.036 